\title{
QUE TIPO DE DIÁLOGO PROMOVE O BEM-ESTAR E O DESENVOLVIMENTO DOS ESTUDANTES?
}

\begin{abstract}
ANNE DIZERBO
https://orcid.org/0000-0001-5815-1950

Université Rennes 2. CREAD-EA 3875

Université de Cergy Pontoise - Laboratoire BONHEURS

BÉATRICE MABILON-BONFILS

https://orcid.org/0000-0002-2810-1554

Université de Cergy Pontoise - Laboratoire BONHEURS

RESUMO

Esta contribuição interroga as condições de bem-estar e de desenvolvimento oferecidas aos alunos pela escola, que se situam para além das dimensões fisicas e materiais, vinculadas a essas noções, em suas perspectivas filosóficas de emancipação. Apresenta um dispositivo de pesquisa-intervenção destinado a iniciar um diálogo entre duas turmas de estudantes do ensino médio e pesquisadores, através de um site científico participativo, em torno da questão: "Será a escola um lugar de seleção social?". Utilizando marcas digitais das trocas entre os diferentes interlocutores, escritos argumentativos dos alunos e entrevistas biográficas, trata-se de compreender os efeitos a curto e a longo prazo dos diálogos sobre o bem-estar dos alunos e sobre a elaboração de um ponto de vista singular favorável ao desenvolvimento de um poder agir sobre o percurso de orientação numa perspectiva de realização.
\end{abstract}

Palavras-chave: Pesquisa biográfica. Saber-relação. Ciências participativas. Autoria.

\section{ABSTRACT WHAT KIND OF DIALOGUE TO PROMOTE THE WELL- BEING AND DEVELOPMENT OF STUDENTS?}

This contribution questions the conditions of well-being and development offered to pupils by school, beyond the physical and material dimensions linked to these notions, in their philosophical perspectives of emancipation. It will present a research-intervention mechanism aimed at initiating a dialogue around the question: "Is school a place of social selection?" between two classes of secondary school students and researchers, through a participatory science site. Using 
digital traces of the exchanges between the various interlocutors, argumentative writings by pupils and biographical interviews, the aim will be to understand the short- and longer-term effects of the dialogues implemented on the well-being of pupils and on the development of a singular point of view, that can develop impowerment acting on the path of orientation in a fulfilling perspective.

Keywords: Biographical research. Relational knowledge. Participatory sciences. Authorization.

\section{RESUMEN ¿QUÉ TIPO DE DIÁLOGO PARA PROMOVER EL}

\section{BIENESTAR Y EL DESARROLLO DE LOS ESTUDIANTES?}

Esta contribución cuestiona las condiciones de bienestar y desarrollo que la escuela ofrece a los alumnos, más allá de las dimensiones físicas y materiales vinculadas a estas nociones, en sus perspectivas filosóficas de emancipación. Presentará un mecanismo de investigación-intervención destinado a iniciar un diálogo en torno a la pregunta: “¿Es la escuela un lugar de selección social?” entre dos clases de estudiantes de secundaria e investigadores, a través de un sitio de ciencia participativa. A través de las huellas digitales de los intercambios entre los distintos interlocutores, los escritos argumentales de los alumnos y las entrevistas biográficas, se tratará de comprender los efectos a corto y largo plazo de los diálogos realizados sobre el bienestar de los alumnos y sobre el desarrollo de un punto de vista singular favorable al desarrollo de una capacidad de actuar en el camino de la orientación en una perspectiva satisfactoria.

Palabras Clave: Investigación biográfica. Conocimiento de las relaciones. Ciencia participativa. La autoría.

\section{RÉSUMÉ QUEL DIALOGUE POUR FAVORISER LE BIEN-ETRE ET L'EPANOUISSEMENT DES ELEVES?}

Cette contribution interroge les conditions de bien-être et d'épanouissement offertes aux élèves par l'école, au-delà des dimensions physiques et matérielles liées à ces notions, dans leurs perspectives philosophiques d'émancipations. Elle présentera un dispositif de recherche-intervention visant à initier un dialogue autour de la question : " L'école est-elle un lieu de sélection sociale ? » entre deux classes de lycéens de seconde générale et des chercheurs, par l'intermédiaire d'un site de sciences participatives. À partir des traces numériques des échanges entre les différents interlocuteurs, d'écrits argumentatifs d'élèves et d'entretiens biographiques, il s'agira de comprendre les effets à court et à plus long terme des dialogues mis 
en œuvre sur le bien-être des élèves et sur l'élaboration d'un point de vue singulier favorable au développement d'un pouvoir d'agir sur le parcours d'orientation dans une perspective épanouissante.

Mots-clés : Recherche biographique. Savoir-relation. Sciences participatives. Auteurisation.

\section{Introdução}

Como a escola pode oferecer condições de bem-estar ou mesmo tornar-se um lugar de realização e de felicidade? Na França, a questão do bem-estar é muitas vezes entendida em termos de saúde física e de condições materiais por influência da "forma escolar" (VINCENT, 1994) e de sua pregnância. Mas, quando se trata de levar em conta todas as dimensões do sujeito e do seu desenvolvimento, considerando-se perspectivas filosóficas de emancipação, a noção deve ser ampliada para incluir o empoderamento dos sujeitos, o que implica poder tomar posição. Nessa perspectiva, fazemos a seguinte indagação: como podem ser ensinadas certas conquistas sociológicas na escola, particularmente aquelas relativas às desigualdades sociais, sem que elas se tornem, mais especificamente para os estudantes da classe trabalhadora, determinismos propícios à violência simbólica e ao fatalismo ou ainda formas de poder para o professor? De fato, como mostram os resultados recorrentes do Programa Internacional de Avaliação de Estudantes [Programme for International Student Assessment] (PISA), entre as questões vivas da escola, particularmente das escolas francesas em relação a outros países desenvolvidos, está a das desigualdades sociais, assumida pela sociologia crítica.

Apresentaremos aqui um dispositivo de pesquisa-formação implementado em duas escolas do ensino médio e coordenado por uma pesquisadora do laboratório Bonheurs ${ }^{1}$

1 Laboratório Bien-être, Organisations, Numérique, Habitabilité, Éducation, Universalité, Relation, Savoirs (Bonheurs) - Bem-estar, Organizações, Digital, Habi- e uma pesquisadora-professora de francês. 0 dispositivo se assemelha a uma pesquisa-intervenção, mas a ideia de formação permite incluir ao mesmo tempo os pesquisadores, que se formam ao identificarem a recepção, plural e complexa, de saberes provenientes da pesquisa; os formadores, que utilizam o dispositivo de pesquisa como procedimento pedagógico e os formandos, que se tornam atores de sua formação, na lógica das ciências participativas.

As pesquisadoras reuniram duas turmas de 28 alunos, com aproximadamente 15 anos de idade, matriculados no segundo ano do ensino médio numa escola da província, e uma equipe de pesquisadores em educação, através de um site de ciências participativas. 0 dispositivo, que se inicia por um diálogo em torno da pergunta - "A escola é um lugar de seleção social?" - coloca os alunos na posição de sujeitos -interlocutores, com o objetivo de construírem saberes e transformarem suas formas de agir. Nesse sentido, a questão das desigualdades escolares, levantada pelas vozes de interlocutores legítimos - os alunos -, estimulados por pesquisadores que as levam a sério, foi pensada como um vetor de empoderamento, de emancipação e de bem-estar.

Tomando como base o intercâmbio digital entre os alunos e a comunidade científica, assim como escritas argumentativas produzidas pelos alunos e entrevistas biográficas, o artigo se propõe a compreender os efeitos a

lidade, Educação, Universalidade, Relações, Saberes, EA 7517 de CY, Paris Université de Cergy Pontoise. 
curto e longo prazo do confronto entre as representações dos alunos e as dos pesquisadores, articulando a enunciação socializada de experiências pessoais - interesse e prazer - e a elaboração de uma opinião singular sobre a qual se apoiam para construir um poder agir sobre o próprio percurso, particularmente em termos de escolha de orientação profissional. Para tanto, no primeiro momento definiremos o quadro teórico e metodológico no qual se inscreve a pesquisa-intervenção e, em segui$\mathrm{da}$, apresentaremos os resultados da implementação do referido dispositivo.

\section{Saber-relação e pesquisa biográfica, alavancas de empoderamento e/ou de pesquisa?}

O quadro paradigmático do dispositivo de pesquisa fundamenta-se na noção teórica de saberes-relações (DURPAIRE; MABILON-BONFILS, 2014), que constituem a base de um esquema de interpretação global para dar sentido aos modos e às formas de implicação dos atores potencialmente envolvidos no seio do dispositivo. No mundo social, em função dos contextos, situações, eventos etc., os saberes estão sintonizados com usos práticos, permitindo às pessoas que os mobilizam de se colocarem em relação com o outro e com o mundo. 0 contexto no qual emerge a noção de saberes-relações se baseia numa tripla virada: uma virada digital, que modifica a maneira como os saberes são produzidos e disseminados; uma virada global, que altera a razão de ser da escola, que já não se reduz ao ensino e uma virada normativa, que transforma a maneira como as regras são construídas (DURPAIRE; MABILON-BONFILS, 2014). Consequentemente, essa renovação permanente do significado que os atores dão a suas práticas sociais não só abala as formas de compartilhamento dos saberes, como também transforma a maneira individual e coletiva de construir significado (COLINET; GADRAS, 2019). A noção de saberes-relação visa circunscrever a relação de influência recíproca que se dá entre o saber e a relação. Sua definição interroga a forma como um sujeito se vê enquanto um ser-em-relação face aos saberes que ele mobiliza numa determinada situação. "O termo saber-relação referese, antes de tudo, à relação dos saberes: é a ideia de uma circulação estendida dos saberes [...]" (DURPAIRE; MABILON-BONFILS, 2014, p. 175). Isso reexamina, primeiramente, a função tradicional da escola e de suas práticas, evidenciando que o aluno acumula cada vez mais saberes fora dela. Em segundo lugar, "a relação saber-relação assume uma dimensão ativa quando essa relação induz um saber da relação" (ibid., p. 177). Os saberes-relações podem ser vistos como ferramentas operacionais para apoiar o relacionamento e orientar a ação. Trata-se de interrogar se a concepção de dispositivos destinados a promover a "felicidade" na escola implicaria levar em conta os saberes que os alunos dispõem e desenvolvem para construir e re-inventar outras relações com o saber, com os outros e consigo mesmo.

Levanta-se, assim, a questão do vínculo entre saber científico, políticas públicas e práticas sociais, que se coloca de modo ainda mais agudo nas ciências humanas e sociais e, especificamente, nas ciências da educação e da formação. Para compreender essa questão, o laboratório Bonheurs iniciou uma abordagem baseada em duas alavancas:

- Conceptualizar o saber-relação (MABILON-BONFILS, DURPAIRE, 2014); e

- Conceber círculos de participação (CALLON, LATOUR, 1988) com profissionais e pessoas interessadas (SCHEMEIL, 2012).

No mundo social, os saberes estão vinculados a usos práticos, permitindo aos indivíduos que os mobilizam entrar em relação com os 
outros, de agir com e sobre o mundo. (DURPAIRE; MABILON-BONFILS, 2014). Nesse contexto, surge a noção de saberes-relações, ancorada numa dupla constatação: a multiplicação do potencial de produção e difusão de saberes com a virada digital em nossas sociedades e a renovação permanente do sentido que os atores dão às suas práticas sociais com a virada normativa das sociedades transmodernas (MABILON-BONFILS, 2018). Desde então, foram afetadas as formas de compartilhar o saber, assim como a maneira individual e coletiva de construção do sentido. Na contemporaneidade, a relação está marcada pela des-temporalização (ela é imediata) e pela des-espacialização (ela se libera da distância). 0 termo "saber -relação" designa, portanto, em primeiro lugar, a relação dos saberes: é a ideia de ampla circulação pelo movimento crescente de pessoas e de bens. 0 saber não pode mais ser concebido dentro dos limites de uma disciplina isolada das demais. Também não é mais possivel reservá-lo a uma elite, privando-o da maioria.

Em segundo lugar, o saber-relação revestese de uma dimensão ativa quando a relação dos saberes induz um saber da relação. A relação dos saberes refere-se ao saber conectado ao mundo no qual ele se impõe objetivamente. O saber da relação é a consciência da relação, que se aprende, se trabalha, se constrói a partir de um dado bruto. É nessa travessia que o professor encontra sua legitimidade, o sentido de sua vocação: transformar a relação dos saberes em saber da relação. A abertura dos saberes - opening information em inglês - traz consigo novos desafios: ter consciência da relação induz igualmente uma ética da relação, que é exatamente o que deve ser ensinado: “Eu existo e progrido porque estou conectado aos outros". Esse saber da relação é, portanto, um poder-relação. A espécie humana se diferencia das demais por saber que deve a outros o que sabe. Se o saber comum nos conecta, a relação é doravante o objeto de um saber comum. Com efeito, nenhuma profissão tem o monopólio do saber e um aluno pode deter informações antes que o professor as traga à sala de aula. Em outras palavras, a tomada de consciência do saber-relação é a possibilidade de transformar a história-relação em poder-relação, a consciência de que o saber e o poder resultam de um compartilhamento democrático.

A ideia de círculos de participação vem da sociologia da tradução, conforme Akrich, Callon, Latour (2006). A relação entre pesquisa e formação não pode ser simplesmente colocada como uma questão de transferência de saberes, mas como a produção de um espaço coletivo para o confronto dos saberes e de práticas em fóruns híbridos. 0 top-down é ineficiente. Não basta a existência de práticas de valorização dos saberes, de lugares reais ou virtuais de fontes disponíveis, de instrumentos e de pesquisas colaborativas para que os profissionais se apoderem deles. É o que todas as sucessivas pesquisas demonstram, inclusive o livro "Para que servem as ciências educacionais?" de Mabilon-Bonfils e Delory-Momberger (2019). Todas as disciplinas estão implicadas nessa constatação. Uma comunidade não se decreta. É a própria ideia de uma organização aprendente ou de uma sociedade aprendente inclusiva que está em jogo na noção de bem -estar e, portanto, de ação como postulado por Freire (2013).

As ciências participativas, que tiveram nos últimos dez anos um rápido desenvolvimento - aumento no número de projetos de pesquisa e crescimento de publicações científicas - têm permitido aos atores sociais desenvolver seu poder de agir e fundamentar sua opinião para fazer escolhas. "As ciências participativas são definidas como formas de produção de conhecimentos científicos e das quais participam ativa e deliberadamente pessoas não-cientistas-profissionais, quer se trate de indivíduos 
ou de grupos", como sugerem Houllier, Joly e Merilhou-Goudard (2017). Nessa perspectiva, trata-se de imaginar condições propícias ao diálogo entre pesquisadores, formadores, professores, alunos e as redes de ensino, criando espaços de participação (AKRICH, CALLON, LATOUR, 2006).

É com esse objetivo que o laboratório Bonheurs oferece um espaço coletivo para o confronto de saberes e de práticas. O propósito é abrir a discussão sob a forma de deliberação conjunta, em que todos podem propor sugestões, pistas, definir um subtema para discussão: bem-estar, avaliação, arquitetura escolar, saúde, desigualdades na escola, relações escola/família etc. A questão que se coloca é: a concepção de dispositivos visando promover a felicidade na escola não implicaria levar em conta os saberes-relações que os alunos têm e desenvolvem para construir e reinventar modalidades de vida coletiva na escola? Os resultados produzidos pelos pesquisadores das ciências humanas e sociais podem impactar sobre os temas investigados nas pesquisas? Ou, mais amplamente, eles podem modificar e influenciar práticas sociais em escala mais global, desde que essas investigações tenham uma certa difusão em termos de popularização? Quais são os vínculos entre ciências, reflexividade e capacidade de agir - empoderamento - no campo da educação e formação? Os conhecimentos assim produzidos influenciam o imaginário e a capacidade de se projetar, individual e coletivamente, em um futuro desejável? A literatura sobre as ciências participativas distingue diferentes niveis de participação desde a informação até a capacitação (ARNSTEIN, 1969) e identifica dois tipos de beneficios (SAUERMANN \& FRANZONI, 2015; CHEVALIER \& BUCKLES, 2013) de ordem cognitiva ou de ordem social ou societal.

Se os saberes-relações são concebidos como uma ferramenta eficaz para apoiar a re- lação e orientar o agir, isso se faz mediante os círculos de participação. Trata-se, assim, de propor uma reflexão coletiva sobre as modalidades de partilhar saberes e se perguntar se "pontos comuns" são possíveis?

A abordagem está baseada numa engenharia da felicidade, ou seja, um procedimento de coconstrução/coconcepção, pelos pesquisadores e profissionais, de dispositivos mobilizadores de saberes de diferentes natureza - saberes de pesquisa, saberes de expertise, saberes de ação, saberes profissionais -, visando melhorar uma ou várias dimensões do bem-estar, definidas por alunos, professores, profissionais de mediação ou pais de alunos, cujo impacto é investigado na pesquisa. Para o pesquisador, a engenharia produz saberes de pesquisa; para o profissional, saberes de ação; para estudantes, profissionais ou seus pais, potencialmente, uma melhoria no bem -estar escolar. Ou mesmo, segundo a teoria da tradução de Latour (2005), a validação dos saberes não ocorre apenas num quadro puramente científico, mas por sua retomada e sua "tradução social fora do laboratório" (AKRICH, CALLON, LATOUR, 2006). E essas traduções têm por consequência uma permanente evolução das identidades dos atores e uma contínua reconstrução do campo. Numa tal engenharia, os atores com perfis e status profissionais diversos (AKRICH, CALLON, LATOUR, 1991; DEROUET, 2002; LATOUR, 2005) se comprometem trazendo seus interesses, sua experiência e seus saberes. De fato, os processos coletivos só existem mediante a implicação individual e interessada de cada participante no trabalho comum e num espaço simbólico de encontros. Inversamente, essa implicação é renovada mediante os efeitos do trabalho coletivo (LEGROS, 2008), o que pode ser chamado de produção de um Comum, no sentido de um recurso partilhado coletivamente por uma comunidade que estabelece regras com a finalidade de pre- 
servar e perenizar, ou até de aperfeiçoar esse recurso oferecendo a possibilidade do direito de ser utilizado por todos. É por esse prisma teórico da pesquisa biográfica em educação, que os saberes-relações foram testados. De fato, é nesse campo teórico que as duas autoras deste artigo, pesquisadoras em ciências da educação, situam o dispositivo que implementaram com os estudantes. A especificidade da pesquisa biográfica em educação, segundo Delory-Momberger (2009), é buscar apreender a elaboração da experiência enquanto escrita da vida: "essa capacidade antropológica segundo a qual os homens percebem sua vida e ordenam sua experiência nos termos de uma razão narrativa". Ainda segundo Delory-Momberger (2020), a narrativa performativa é o que permite ao humano compreender e dar forma a suas próprias ações e a dos outros. Ela possui ainda uma função geradora. De fato, se concebemos o mundo real adequando-o às histórias que contamos a nós mesmos, graças às normas em vigor, elas também nos permitem contestar e ultrapassar essas normas para criar outras.

Nossas representações estão associadas, por um lado, a narrativas construídas singularmente em função de nossas experiências e de narrativas modalizadoras nas quais elas adquirem sentido: narrativas familiares, sociais e midiáticas (DIZERBO, 2020). Ao multiplicar os modelos disponíveis, a socialização de narrativas das experiências se mostra propícia, no mesmo movimento, à compreensão e à interpretação tanto das próprias experiências, quanto das experiências dos outros. A narração socializada constitui-se uma ocasião de "refigurações", segundo Ricœur (1986), ou seja, de apropriações heterobiográficas da narrativa dos outros no mundo de experiências e de representações, podendo potencialmente transformar os modos de agir a elas vinculados.

Nesse sentido, envolver os alunos numa confrontação com suas próprias representa- ções, com aquelas de seus pares e as dos pesquisadores, pareceu favorável à elaboração de seu ponto de vista, na condição de que eles fossem considerados desde o início como interlocutores de pleno direito, participando ativamente do processo de apropriação e de construção de conhecimentos. Para tanto, a pesquisa biográfica convida os pesquisadores a tecerem com os atores uma relação de confiança e de respeito, centrada numa lógica dialógica de escuta e de partilha horizontal (DELORY-MOMBERGER, 2014). Essa relação permite que os participantes desenvolvam uma compreensão mais aprofundada de suas experiências sem ameaçar sua identidade, para se inscrever numa postura de autores e desenvolver o sentimento de poder agir, o que contribui para seu bem-estar.

\section{Um dispositivo de pesquisa- formação: montagem, resultados e discussão}

A montagem do dispositivo de pesquisa-formação

Nesse contexto, a pesquisadora-professora de francês propôs a seus alunos de segundo ano de se apropriarem do dispositivo, enquanto a pesquisadora do laboratório Bonheurs pedia aos pesquisadores de diferentes laboratórios de interagirem com os alunos.

Tratava-se de duas classes muito heterogêneas, uma delas tinha um nível bastante fraco e a outra um nivel melhor, nas quais uma grande parte dos alunos discutia muito frequentemente sobre as questões levantadas pelas aulas de francês, mas, frequentemente, sem se escutarem mutuamente ou argumentarem de forma pertinente, limitando-se a uma exposição pouco fundamentada das representações que eles tinham dos assuntos evocados, enquanto outros alunos pouco se envolviam oralmente, permanecendo em silêncio. 
Foi proposto a essas duas turmas de se engajarem numa reflexão aprofundada sobre um tema relacionado à sua escolaridade, dando lugar a um debate entre eles e a um diálogo deles com pesquisadores em ciências humanas e sociais, no site de ciências participativas, durante um período limitado de seis semanas. Os alunos foram informados que suas produções escritas constituiriam dados anônimos da pesquisa sobre os efeitos do confronto de representações, possibilitado pelo debate e que eles teriam acesso à interpretação dos dados realizada pelos pesquisadores.

0 desafio era permitir que os alunos construíssem uma opinião própria sobre a questão escolhida por eles mesmos - "A escola é um lugar de seleção social?" - no momento em que se preparavam para escolher no ano seguinte a orientação para uma área de estudo - ciências, literatura, tecnologia ... - ou um direcionamento profissional. Nesse contexto, era provável que a interação coletiva pudesse fazer evoluir suas representações para inscrevê-las numa perspectiva mais lúcida.

Observaremos então os efeitos da articulação entre a enunciação socializada das experiências singulares dos alunos e a construção de poder agir mais lucidamente sobre seu percurso escolar e a orientação vocacional, apoiando-se sobre o aprimoramento de suas competências em termo de debate, sobretudo na capacidade de levar em conta a opinião do outro e de se apoiar sobre os conhecimentos para fortalecer seu ponto de vista. O trabatho realizado sem a estrutura do dispositivo se inscrevia na perspectiva dos programas de língua francesa, destinados à aquisição de habilidades que thes permitissem "aprofundar e exercer o julgamento e o pensamento crítico"; de "desenvolver a reflexão pessoal e uma argumentação convincente, tanto na escrita, quanto na oralidade" (FRANÇA, 2019).

Quando os alunos descobriram o site de ciências participativas, construído pelo laboratório Bonheurs, eles escolheram entre as várias questões ali levantadas a de falar da escola como um lugar de seleção social, justamente quando eles se preparavam para fazer uma escolha de orientação profissional decisiva. Eles foram então convidados a refletir sobre essa questão e se prepararem para respondê-la pela primeira vez no quadro de um debate em sala de aula. No dia do debate, foi solicitado, primeiramente, que redigissem um parágrafo para responder à pergunta. 0 desafio era permitir que formalizassem sua primeira opinião sobre o assunto antes de entrar em discussão com seus pares e, para o pesquisador, de ter um acesso às suas representações sobre o assunto antes do debate.

A discussão foi então realizada nas duas turmas, cada uma divida em dois grupos para facilitar a comunicação. Enquanto um grupo debatia, o outro era colocado em situação de observação e de avaliação da qualidade do debate. Na semana seguinte, os alunos foram convidados a irem à sala de multimeios para postar suas opiniões no site de ciências participativas.

Os textos iniciais, por eles produzidos, thes foram devolvidos e eles puderam ou modificá - los ou digitalizá-los sem transformações. Eles tiveram então duas semanas para ler as propostas dos colegas das duas turmas e realizar trocas com os pesquisadores, que os convidavam frequentemente a ampliar sua reflexão, mediante uma pergunta ou a indicação de uma leitura.

Essas interações em vários níveis deveriam em princípio fazer evoluir suas representações para construírem um ponto de vista mais fundamentado, de modo a favorecer uma escolha de orientação vocacional lúcida, permitindo-lhe realizar-se. 0 efeito das interações foi avaliado graças à produção de um texto argumentativo elaborado durante as aulas de fran- 
cês. Finalmente, as entrevistas realizadas com alunos voluntários sobre a experiência vivida nessas interações concluíram o uso do dispositivo.

Os dados analisados estão, portanto, constituídos por três produções escritas - duas manuscritas e uma digital, postada no site de ciências participativas -, tendo por finalidade responder à pergunta: "A escola é um lugar de seleção social?"; pelas observações do comportamento dos alunos durante a implementação do dispositivo e pelas anotações tomadas durante as entrevistas realizadas com alunos. É preciso ressaltar que em nenhum momento a correção gramatical e ortográfica dos textos foi considerada como objeto de avaliação para que os alunos pudessem se expressar sem restrições formais.

As contribuições do debate em sala de aula podem ser medidas pelas mudanças entre as primeiras produções dos alunos, feitas antes do debate em sala de aula, e os textos postados on-line alguns dias depois do debate. o que se observa é que a metade dos alunos modificou o texto original, acrescentando frequentemente um argumento utilizado na aula por outro aluno ou mudando completamente de ponto de vista, como mostram as duas primeiras produções escritas de Jack:

A escola cria juízos e divisões entre os alunos.

Jack (produção escrita 1) - Na escola, os alunos se dividem em grupos com relação às suas afinidades, mas também com relação às roupas que vestem. Se você não for como os outros, com um comportamento estranho, você fica de fora. Por exemplo, no esporte, você vai preferir ficar com alguém que é forte em vez de mais fraco, mesmo que não seja culpa dele.

Jack (produção escrita 2) - Por um lado, eu diria não, porque não há discriminação [pelos] professores e todos nós temos direito à educação. Alguns subsídios são dados para permitir a cada criança de ser escolarizada, pouco im- porta a situação social. Entretanto, por outro lado, nós devemos todos ter acesso à mesma educação, ora a situação financeira de nossos pais pode ter um impacto em nossos estudos. Isto pode abrir mais ou menos possibilidades para nosso futuro (especialmente para escolas de prestígio2) [...].

Para outros alunos, isso se tratava sobretudo de nuances, mas a primeira etapa do dispositivo já favorecia uma apropriação reflexiva da questão discutida e um movimento no modo de pensar.

As contribuições do conjunto das interações realizadas com os pesquisadores pelas duas turmas, que os alunos tomaram conhecimento pelo site de ciências participativas, podem ser avaliadas pelas notáveis evoluções que surgiram entre a segunda e a terceira produção escrita, já mencionadas. A observação das escritas dos 49 alunos que escreveram a última versão do texto mostra que 45 deles enriqueceram seus argumentos; 35 se basearam nas observações dos pesquisadores ou em documentos por eles apontados; 10 alunos restantes retomaram sobretudo argumentos apresentados por seus pares.

O dispositivo também proporcionou uma oportunidade para rever a pergunta que, para muitos deles, se inscreveu num primeiro momento numa dimensão puramente relacional, e passou então a integrar dimensões institucionais, culturais e econômicas, ampliando suas perspectivas.

Esmeralda (excerto da 1ạ produção escrita) [...] se uma pessoa, que vamos chamar de $x$, não está vestida como o resto de seu grupo de amigos, ela pode ser rejeitada, excluída [...] as pessoas que se vestem como todo mundo com roupas super caras não querem sair com pes-

2 Na França, as escolas de ensino superior, ou les grandes écoles - tais como a École Nationale d'Administration (ENA), École Nationale de Magistrature, École Polytechnique -, que dependem de outros Ministérios e não do Ministério da Educação, são mais seletivas pois exigem um concurso de acesso e gozam, historicamente, de mais prestígio do que a universidade. 
soas que têm roupas sem marca ou então que têm menos dinheiro do que elas.

Esmeralda (excerto da 3a produção escrita) Para mim, a escola é um lugar de seleção social, é uma instituição estatal que tem por vocação dar a todas as crianças a chance de serem educadas e de serem bem sucedidas, independentemente da classe social a que pertencem. As escolas são acessiveis a todos. São os alunos e às vezes até mesmo os professores que fazem da escola um lugar de seleção social. [...] Depois do ensino médio, quando os alunos querem fazer medicina ou outra escola de prestígio, nem sempre têm possibilidades, porque as escolas de ensino superior são, na maioria das vezes, muito caras. A gente observa então que existe uma diferença social entre as crianças que vêm meios privilegiados e as que vêm de um meio social desfavorecido.

Esse deslocamento favoreceu a possibilidade de estabelecerem relações entre sua própria experiência escolar com um posicionamento lúcido em termos de orientação, favorável à sua realização a longo prazo. Mas o dispositivo também proporcionou uma oportunidade de propor um trabalho que melhorasse, a curto prazo, o bem-estar dos alunos.

A observação das atitudes dos alunos em sala de aula, pelo professor, permite afirmar que para 23 alunos, que habitualmente se envolvem menos nas aprendizagens, a participação aumentou significativamente durante as atividades propostas pelo dispositivo com relação a outras atividades realizadas em paralelo. A terceira produção escrita também foi de melhor qualidade do que as de suas produções habituais de redação, apesar das dificuldades persistentes provenientes sobretudo de lacunas metodológicas na abordagem da argumentação. Esses resultados evidenciam um interesse mais importante dos alunos, reforçado pelas entrevistas que lhes foram propostas no final do dispositivo e aceitas pela maioria dos que estavam presentes.
De fato, sobre os 45 alunos que se expressaram, 35 enfatizaram sem reservas o prazer experimentado durante a implementação do dispositivo; 6 alunos emitiram opiniões nuançadas, destacando tanto o prazer e o interesse experimentado durante os intercâmbios, quanto as dificuldades técnicas encontradas nas trocas com os pesquisadores; e apenas quatro alunos emitiram uma opinião negativa sobre o trabalho implementado. Dois deles, que são bons estudantes, consideraram o debate estéril. É interessante constatar que suas falas veiculam uma representação abrangente, bem mais fatalista e determinista sobre a questão abordada, o que explica sua posição e a dificuldade em subjetivar o exercício de debate proposto, tanto quanto seu percurso escolar:

Deron - Tem gente que não é muito inteligente e tem gente inteligente.

Valde Sullivan - O estudante que dispõe de um quadro familiar melhor do que o de um outro estudante tem mais chances de sucesso escolar.

Os outros dois alunos, menos "escolares", mencionaram, por sua vez, o excesso de trabalho que representavam as trocas no site e as dificuldades de compreensão das intervenções dos pesquisadores ou de suas propostas de leitura.

Dezessete alunos mencionam, em primeiro lugar, o prazer que tiveram nas diferentes fases do trabalho. Esse argumento não pode ser negligenciado na medida em que ele contribui para motivar os estudantes em suas aprendizagens e é importante notar que isso só acontece num segundo plano, depois de mencionarem o interesse provocado, é o caso de 28 estudantes. A entrevista coletiva não permitiu aprofundar todos os motivos do interesse e do prazer vividos, mas alguns alunos associaram o dispositivo à sensação de poder se afirmar enquanto indivíduos graças aos intercâmbios 
e ao engajamento suscitado pela reflexão sobre a sua orientação escolar.

Oito estudantes mencionaram que se sentiram valorizados graças às interações com os adultos-pesquisadores, produtores de conhecimento, que os tratavam com gentileza e respeito; enquanto seis participantes, que pouco aderiram ao dispositivo, enfatizaram o aspecto relacional afirmando que os pesquisadores os haviam desencorajado, sobretudo quando a comunicação lhes parecia injuntiva. Surge, então, uma sensibilidade particular à qualidade da relação estabelecida. Os participantes demonstraram claramente que eles precisam ser vistos como interlocutores de pleno direito, como pessoas mais do que como alunos. Entre os obstáculos mencionados, aparecem também o nível de expectativa dos alunos com relação aos pesquisadores em termos de trabalho - 13 alunos consideraram que não tinham tempo para assumir essa carga de trabalho suplementar exigida em sua escolaridade - ou em termos de compreensão de documentos que thes tinham sido enviado - 7 alunos mencionaram esse fato. Seria, portanto, uma questão de considerá-los capazes de compreender os resultados dos trabalhos de pesquisa ou de enquete, colocando-os, por exemplo, mais ao seu alcance através de sínteses ou de artigos que são em geral mais acessiveis.

Dificuldades de ordem técnica também se constituíram freios ao engajamento ou à persistência do engajamento no dispositivo: 12 alunos tiveram dificuldades de se conectar, seja porque não tinham acesso fácil à internet, seja porque acharam dificil interagir de forma intercalada com os pesquisadores que, às vezes, só intervinham mais de uma semana depois da publicação de seus textos. Depreende-se daí que esse tipo de dispositivo deve ser implementado exclusivamente no contexto de cursos que ofereçam acesso universal à internet e um acompanhamento técnico.
Do ponto de vista dos estados de bem-estar associados ao prazer, evocados pelos alunos, que claramente lhes permitiram aprender, muitas pesquisas demonstram que o mundo sensivel envolve diferentes estados mentais e que os estados de estresse e de bem-estar revelam obstáculos ou, ao contrário, facilitam o processamento de dados ancorados em operações simples e complexas (DAMASIO, 1994). Baseando-se na teorização de Hall (1984), que distingue dois níveis de cultura - manifestas e profundas -, trazidas por um indivíduo, Jaillet (2019) propõe que se instauram nas zonastampão, entre culturas profundas e culturas manifestas, relações comunicativas e culturais consideradas aceitáveis: o que está no centro é fomentar estados sociais e psicológicos capazes de promoverem a produção de dopamina, entre outras coisas, para acompanhar cada indivíduo em direção a aprendizagens que o façam perceber o que Papert apontou como um motor superior de aprendizagem, de modo que a situação seja "Hard Fun". Aqui a ideia de escolher o que debater, de utilizar uma plataforma de intercâmbio e de ser interlocutores legítimos para os pesquisadores foi capaz de se tornar uma força motriz.

Além disso, o site de ciências participativas foi projetado numa lógica de "sensibilidade educativa", e de uma "sensibilidade ativa" (JELLAB, MARSOLLIER, 2018), em que os pesquisadores são sensiveis aos sinais enviados pelos alunos e à qualidade da relação entre eles - mesmo curta e epistolar - associada à sensibilidade da pesquisadora-professora de francês que foi capaz de por em prática no contexto da sala de aula. Os alunos eram interlocutores legítimos: sua palavra foi levada a sério. Em um contexto marcado pelo crescimento de di-

3 Traduzimos o termo "bienveillance educative" por "sensibilidade educativa". Consideramos ser essa a opção mais adequada dentre as demais propostas (benevolência, altruísmo...) de tradução para o português. N.T. 
ferentes formas de vulnerabilidade e pela necessidade de lidar com as fragilidades sociais e subjetivas, elas próprias vinculadas a um contexto sociopolítico e econômico específico, a sensibilidade é um motor de emancipação. Os pesquisadores e membros profissionais do laboratório Bonheurs adotaram globalmente uma postura de trocas, de questionamentos, e não de julgamento ou de avaliação das observações. Tratar-se de uma questão "socialmente viva", a das desigualdades escolares, na interação com os alunos, alguns provenientes de meios populares, é um desafio. O objetivo era obviamente o de não fomentar fatalismo, mas sobretudo de equilibrar a baixa autoestima de muitos desses alunos, despertando um sentimento de autoconfiança nas interações em que suas palavras eram levadas em conta.

\section{Conclusão}

As contribuições do debate realizado em sala de aula e no site de ciências participativas emergem, acima de tudo, enquanto partiIha das representações que vieram claramente enriquecer e transformar posições singulares. Embora o dispositivo, tal como foi implementado, não permita afirmações categóricas e sua experimentação mereça novos desenvolvimentos, os resultados levam pelo menos a formular hipóteses a serem validadas no âmbito de uma pesquisa mais aprofundada.

O debate seria de natureza a modificar não apenas as representações, mas também o agir dos alunos. Colocados na posição de autores de sua própria opinião no debate crucial sobre as interações entre o sistema escolar e a seleção social, eles se apropriariam mais de seus percursos escolares e poderiam reexaminar suas escolhas de orientação escolar, que para muitos se baseiam em concepções deterministas e fatalistas, alimentando muitas vezes um sentimento de impotência:
Claudine: cada indivíduo é categorizado, sempre foi assim, e isso nunca vai mudar.

Kimk: Muitas vezes, os caminhos profissionais como um CAP é menos bem percebido do que as vias gerais, porque o que gira em torno do geral é necessariamente mais difícil.

Certas representações internalizadas alimentam esse sentimento de impotência e também, às vezes, um sentimento de revolta.

Olaf: A orientação dada pelos 'conselheiros de orientação' (que só dizem merda) [...] e que só fazem nos confundir. Pessoalmente, é preciso que me expliquem como é que alguém que não te conhece pode dizer o que você deve fazer.

No entanto, esses sentimentos não parecem servir ao propósito de subjetivar nem o percurso escolar nem a orientação. 0 debate sobre questões relacionadas à orientação dos alunos, permitindo um exame de pontos já bem conhecidos e sobre os quais se baseiam as escolhas dos alunos, poderia permitir uma transformação dessas escolhas na direção de uma (re)apropriação de aspectos escolares que encorajem o desenvolvimento de um poder agir sobre sua própria existência.

Essa apropriação se apoiaria em interações que proporcionassem aos alunos um reconhecimento do qual precisam para alimentar sua autoestima e que thes possibilite por em movimento seus modos de pensar, de formar sua opinião e de evoluir. Por ser alimentada por adultos externos à escola, que se encontram numa posição social de autoridade em matéria de conhecimento, ela se revelou particularmente importante no dispositivo para se opor às representações dos alunos, cuja construção desde tenra idade se baseia nas de suas famílias e de seus professores, assim como sobre as narrativas veiculadas pelas mídias, determinando frequentemente e em grande parte suas escolhas. Os resultados dessa experiência inicial evidenciam a necessidade de pensar 
- lugar do debate nos processos de orientação escolar, sobretudo com pesquisadores, considerando as possibilidades que se abrem para levar em conta o conjunto das dimensões do tema e seus impactos sobre seu desenvolvimento e sua emancipação.

\section{Referências}

AKRICH, Madeleine; CALLON Michel; LATOUR Bruno. À quoi tient le succès des innovations? L'art de l'intéressement et le choix des porte-parole. Gérer et Comprendre $n^{\circ} 11$, p. 1-19, 1988. Disponible sur: http://annales.org/gc/1988/gc-11-06-88/article-gcjuin-1988.pdf Consulté le: 10 déc. 2019.

ARNSTEIN, Sherry R. A ladder of citizen participation. Journal of the American Institute of Planners, 35, 4, p. 216-224, 1969. DOI: 10.1080/01944366908977225

CHEVAlIER, Jaques M, BUCKLES, Daniel. Participatory action research. Theory and methods for engaged inquiry, London, Routledge, 2013.

COLINET, Séverine; GADRAS, Mike. Peut-on penser le bonheur à l'école? Analyse de la première journée des " petits » bonheurs à l'École. Quels savoirs et savoirs-relations mobilisés? Tréma 52, 2019. DOI: 10.4000/trema.5392

DAMASIO, Antonio R. L'erreur de Descartes: la raison des émotions. Paris: Odile Jacob, 1994.

DELORY-MOMBERGER, Christine. De la recherche biographique en éducation. Fondements, méthodes, pratiques. Paris: Téraèdre, 2014.

DELORY-MOMBERGER, Christine. La condition biographique. Essais sur le récit de soi dans la modernité avancée. Paris: Téraèdre, 2009.

DELORY-MOMBERGER, Christine. Analyse(s) du récit. In: DELORY-MOMBERGER, Christine (dir.). Vocabulaire des histoires de vie et de la recherche biographique. Toulouse: Érès, 2020. p. 275-280.

DEROUET, Jean-Louis. Jeu, loisirs et éducation informelle. Éducation et Sociétés, $n^{\circ} 10, v .2,2002$. Disponible sur: https://www.cairn.info/revue-education -et-societes-2002-2.htm Consulté le: 10 déc. 2019.
DIZERBO, Anne. « Ils l'appellent le collège poubel-

le ». Construire son parcours entre histoire singulière et récits collectifs. Paris: Éditions Téraèdre, 2020.

DURPAIRE, François; MABILON-BONFILS, Béatrice. La fin de l'école. L'ère du savoir-relation. Paris: P.U.F, 2014.

FRANÇA, MINISTÈRE DE L'ÉDUCATION NATIONALE ET DE LA JEUNESSE. (2019). Annexe 1 du BO spécial du 19 janvier 2019. Disponible sur: https://www.education.gouv.fr/bo/19/Special1/MENE1901601A.htm. Consulté le: 10 déc. 2019.

FREIRE, Paulo. Pédagogie de l'autonomie. Toulouse: ÉRÈS, 2013.

HALL, Edward T. La danse de la vie: temps culturel, temps vécu. Paris: Seuil, 1984.

JAILLET, Alain. Cerveau, émotions et bonheurs: apprendre par le « Hard Fun ». Tréma, 52, p. 1-9, 2019. DOI: $10.4000 /$ trema. 5340

JELLAB, Aziz. \& MARSOLLIER, Christophe. (dir). Bienveillance et bien être à l'école. Pour une école humaine et exigeante. Berger Levrault, 2018.

HOULLIER François; JOLY, Pierre-Benoît; MERILHOUGOUDARD Jean Baptiste. Les sciences participatives: une dynamique à conforter. Natures Sciences Sociétés. 25, 4, p. 418-423, 2017. doi: 10.1051/nss/2018005.

LATOUR, Bruno. Reassembling the Social - An Introduction to Actor-Network-Theory, Oxford University Press, 2005.

LEGROS, Valérie. Effets de formation et dynamiques de l'espace d'intéressement. Recherche et formation, (58), p. 85-100, 2008. https://www.cairn.info/ revue-recherche-et-formation-2008-2-page-85.htm

MABILON-BONFILS, Béatrice. DELORY-MOMBERGER, Christine. (dir.). À quoi servent les sciences de l'éducation? Paris: ESF, 2019.

MABILON-BONFILS, Béatrice. L'école est finie ! L'ère transmoderne du savoir-relation et la fin de la transmission. Éducation et socialisation, 47, mars 2018. DOI: $10.4000 /$ edso.2862 
VINCENT, Guy (dir.). L'éducation prisonnière de la forme scolaire? Scolarisation et socialisation dans les sociétés industrielles. Lyon: PUL, 1994.

RICOEUR, Paul. Temps et récit I. Paris: Seuil, 1983.

SAUERMANN Henry \& FRANZONI Chiara. Crowd science user contribution patterns and their implications. PNAS, 112, 3, p. 679-684, 2015. Disponible sur: https://www.pnas.org/content/112/3/679 Consulté le: 10 déc. 2019.

SCHEMEIL, Yves. Introduction à la science politique. Paris: Dalloz, Presses de Sciences Po, 2012.

Recebido em: $14 / 04 / 2020$

Revisado em: 15/08/2020

Aprovado em: 21/08/2020

Tradução - Maria da Conceição Passeggi é pesquisadora de produtividade do Conselho Nacional de Desenvolvimento Científico e Tecnológico (CNPq) - Pq1-Ed, é professora da Universidade Cidade de São Paulo (Unicid), Universidade Federal do Rio Grande do Norte (UFRN).E-mail: mariapasseggi@gmail.com

Béatrice Mabilon-Bonfils é professora da Universidade de Cergy Pontoise; pesquisadora do Laboratório Bien-être, Organisation, Numérique, Habitabilité, Éducation, Universalité, Relations, Savoirs (Bonheurs). E-mail: beatrice.mabilon -bonfils@laboratoire-bonheurs.fr

Anne Dizerbo é pesquisadora do Centre de Recherche sur l'éducation, les apprentissages et la Didactique (Cread-EA) 3875; do Collège International de Recherche Biographique (CIRBE) en Éducation e do Laboratório Bonheurs. Responsável pelo Polo Iniciativas em pesquisa biográfica.E-mail: dizerboanne@sujetdanslacite.org 